\title{
3D Substation Modeling Based on BIM Technology in China
}

\author{
Xiaoqiang $\mathrm{Hu}^{1, \mathrm{a}}$, Baojian $\mathrm{Zhao}^{2, \mathrm{~b}}$ and Chenglei Sun ${ }^{2, \mathrm{c}}$ \\ ${ }^{1}$ School of Economic and Management, North China Electric Power University, Beijing 102206, \\ China; \\ 2 Jinzhou Electric Power Supply Company, State Grid Liaoning Electric Power Supply Co. Ltd, \\ Jinzhou 121001, China. \\ apdrs00@163.com, bzhaobaojian@21cn.com, ${ }^{\mathrm{c}} 277129298 @ q q . c o m$
}

Keywords: BIM, Substation, Modeling, Engineering Quantities

\begin{abstract}
The application of Building Information Modeling (BIM) technology in managing the electric power construction project has not only become possible due to popularization of the technology, but also become necessary as the electric power project's size and complexity increases. In this paper, an electric power project modeling is used as a basis of applying BIM technology and a $35 \mathrm{kv}$ substation is used as the object of study. The framework, process and construction of the electric power library in the BIM modeling are discussed using Revit software, which focuses on the balance of engineering calculation rules of the 2013 edition power engineering quota in the modeling; as it will become the foundation for automatic engineering quantity statistics and BIM modeling standards in power engineering cost management in the future.
\end{abstract}

\section{Introduction}

Building Information Modeling or known as BIM was proposed by Jerry Laiserin. BIM technology has many characteristics such as visualization, coordination, simulation and optimization. It can also carry out virtual construction and information integration with powerful computation and cooperation ability [1,2].

Information is the heart of BIM technology. Thus, by establishing information modeling on the early stage of a project, it can not only be applied to design and construction stage, but also has a dramatic effect on property, operation, maintenance and demolition stages. With that, we can say that the Building Information Modeling works for entire life cycle of a project $[3,4]$. BIM provides a platform for exchanging and sharing information. With the gathered information together, it will provide different parties useful information for the project needs [5,6]. Moreover, the use of BIM technology enhances the efficiency of the project greatly as it does not only eliminate all hidden design dangers that may lead to project delay and waste, but also improves the management for entire project life cycle [7].

That is why authorities pay great attention to the development of building informatization. In the 13th five-year plan, they specifically pointed out to accelerate Building Information Modeling (BIM) application in the engineering and to push forward the standardization of the construction informatization. When compared to construction industry, electric power construction industry and construction industry has some similarities. Due to electric power construction industry's huge investment, technology-demand and high quality requirement, each power construction project is prioritized by the local government and relevant community. Thus, BIM technology application has become extremely urgent in order to improve the level of electrical power engineering management.

The basis of using BIM technology is the modeling of power engineering. In this paper, a 35kv substation is used as an example; and Revit2015 software is used to discuss the framework, the process and the ideas of BIM modeling. 


\section{Overall Thought and Modeling Process of Substation}

The substation is divided into different architecture part which includes wall, column, beam, roof elements, and the structure part which the main task is to place steel. In addition, there are also outbuildings and electrical engineering family (see Fig. 1).

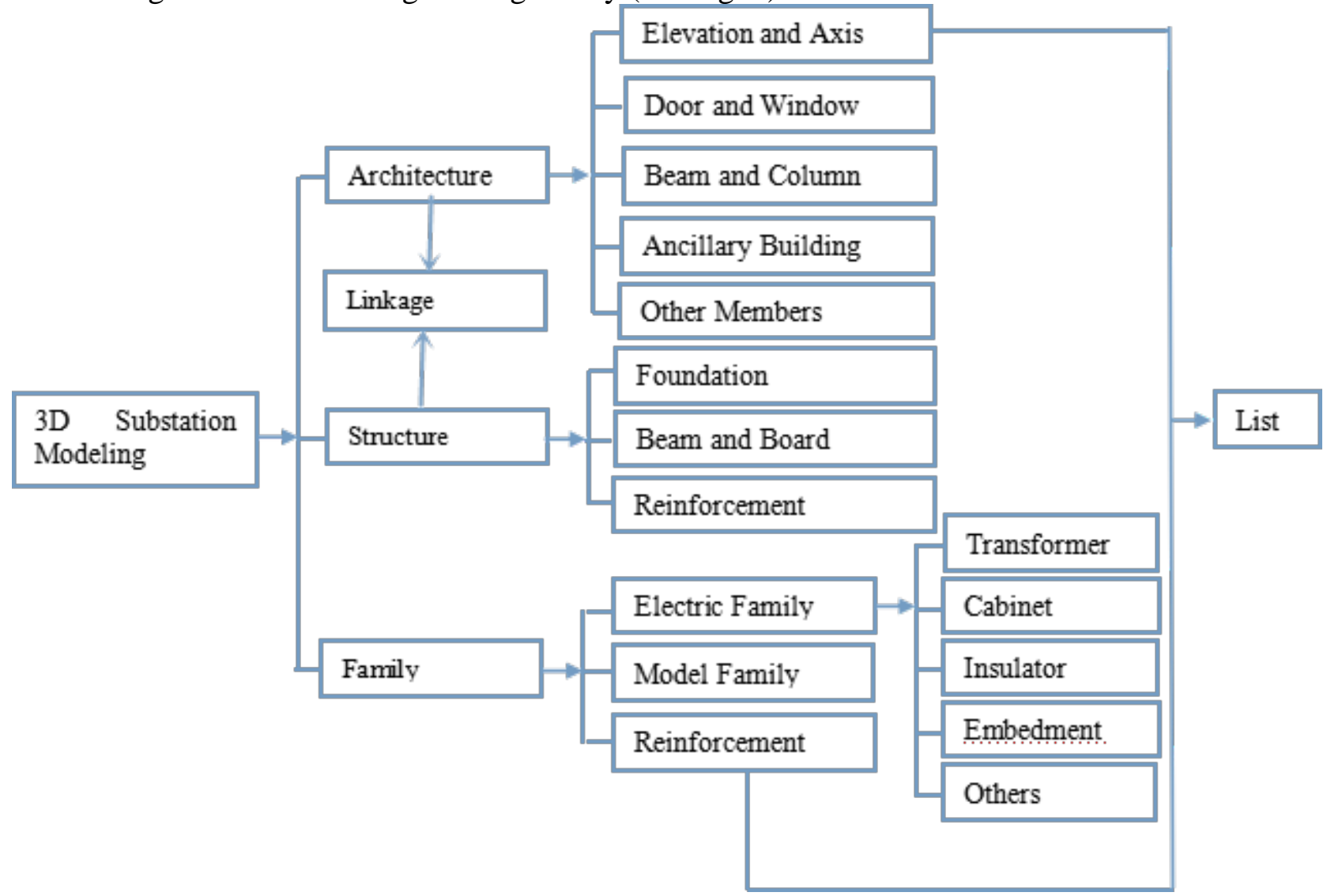

Fig. 1 The modeling process

\section{The Substation Modeling Points}

\subsection{The Main Building}

The main building is a substation building where the staffs live and work. The substation building includes switch room, grounding transformer chamber, condenser room, equipment room, living room and the like. At the bottom of first layer, switch room needs to lay the electrical cables, so we should design the cable trench beforehand.

The cable trench is not only a major feature of substation, but also a difficulty in architecture design and list statistics. We can use wall and floor to build the cable trench, but the process of drawing it is a little bit tedious. Based on estimation norm, the cable trench's fee category is a complex ground and the fee is based on building axis size, we don't need to deduct the cave area and the rule of list statistics is the same as floors. But in the preliminary estimation norm, the cable trench is based on volume to count list, neither wall nor floor can calculate trench's volume, the best solution is to use building volume that is a family type which doesn't have any building property. After using volume modeling, we can calculate its volume and surface area directly in order to meet the demand.

\subsection{The Main Structure}

The main structure's work is to configure the steel. We usually use Revit extension software which is a steel modeling plugin to achieve this work, and through inputting some numbers we can complete simply reinforce the work. For an instance, use the plugin to configure steel for foundation, beam, board and column at first, however, we will need to make some manual adjustment later in order to meet the design requirement due to some inaccuracy. Moreover, the biggest drawback of the plugin is 
it cannot configure the lateral steel for stairs and roof; and we have to spend a lot of time to adjust the steel's length, shape and angle manually, thus it greatly increased the complexity of modeling.

For the complex steel structure, the Tekla software can be a model for others. In 2008, engineers used this software to simulate and to analyze the steel structure frame of the birds nest. Using Tekla, we can accomplish fine modeling and prefabrication to reduce the costs.

\subsection{Family Library Construction}

In Revit2015 software, basic graphic unit such as wall, door and window is called metafile, which is created by family. Family is a parametric component which includes other parameters of free regulation that controls metafile's material, size, location and other information. Other than that, family is the basis and essence of Revit design software, the more the parameter means the more the information we can obtain and the more the embody value of BIM technology. There are five basic commands namely stretching, integration, rotation, lofting and lofting integration that can create all sorts of family files. This project's electrical family libraries include transformer, switchgear, insulator, busbar, fitting, cover and other members. The transformer family see Fig. 2.

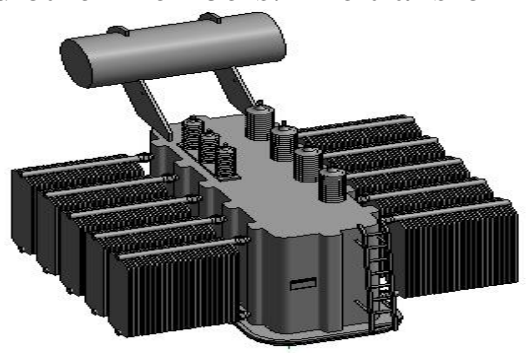

Fig. 2 The transformer family

The family creation is a time-consuming work as we need to know on how to correlate the corresponding family parameters in order to achieve linkage parametric design, and then realized the reuse to improve efficiency is a problem that deserves to be discussed.

\subsection{Quantity Statistics}

Even though we can obtain the project's list automatically (see Table 1) when BIM technology is used in the substation modeling, but some of them still cannot be used directly as fee benchmark. Take beam as example, in 2013 edition's power engineering quota rules, the overlap between beam and board counted as beam, while it is counted as board in Revit own calculation rules,. In order to solve this problem, we have two ways. One way is to reprocess the feedback control information after the design stage exported the different lists to Excel in where we adjust and enhance the data and then import to calculation software. The other way is to familiarize the quota calculation rules in the early stage, and use it as the feed forward control standard in modeling. Then remove the quantities error in the design stage in order to get the correct quantities after modeling. For example, appropriate adjustment in board's boundary line and substitute overlap with beam, through this method we can get a modeling that conform to quota rules. By contrast, the latter is better in many aspects, such as light workload in later stage, step by step in completing the tasks and push forward the change of cost members' focus. 
Table 1 Room list

\begin{tabular}{ccccc}
\hline \multicolumn{4}{c}{$<$ Room List $>$} & \\
A & B & C & D & E \\
\hline Name & Elevatio & Area(Square & Volume(Cu & Girth(Milli- \\
& $\mathrm{n}$ & Metre) & bic Metre) & metre) \\
10kv Switch Room & F1 & 185.28 & 736.65 & 72960 \\
10kv Grounding & F1 & 16.65 & 65.35 & 17320 \\
Transformer Room & & & & \\
Toilet & F1 & 4.07 & 15.64 & 8920 \\
Duty Room & F1 & 9.04 & 35.25 & 12120 \\
Living Room & F1 & 10.95 & 42.81 & 13320 \\
10kv Condenser Room & F1 & 70.86 & 281.02 & 36720 \\
Pump Room & F1 & 44.27 & 128.94 & 29040 \\
35kv Switch Room & F2 & 154.91 & 616.27 & 62800 \\
Reference Room & F2 & 11.46 & 42.94 & 13520 \\
\hline
\end{tabular}

\section{Substation Model}

A $35 \mathrm{kv}$ substation floor space is $389.52 \mathrm{~m}^{2}$ and the total construction area is $769.68 \mathrm{~m}^{2}$. The basic structure form is framework and the foundation is raft structure; and the main structure consist of two-story building, the first layer includes $10 \mathrm{kv}$ switch room, grounding transformer chamber, condenser room and living room, while the other layer includes $35 \mathrm{kv}$ switch room, equipment room, reference room, tool room and so on.

The substation model uses Revit software to achieve architecture and structure model, the software supports IFC standard interface that facilitates the data transfer. Navisworks as a construction simulation software is used to verify the possibility of actual construction. The architecture exploded diagram see Fig. 3.

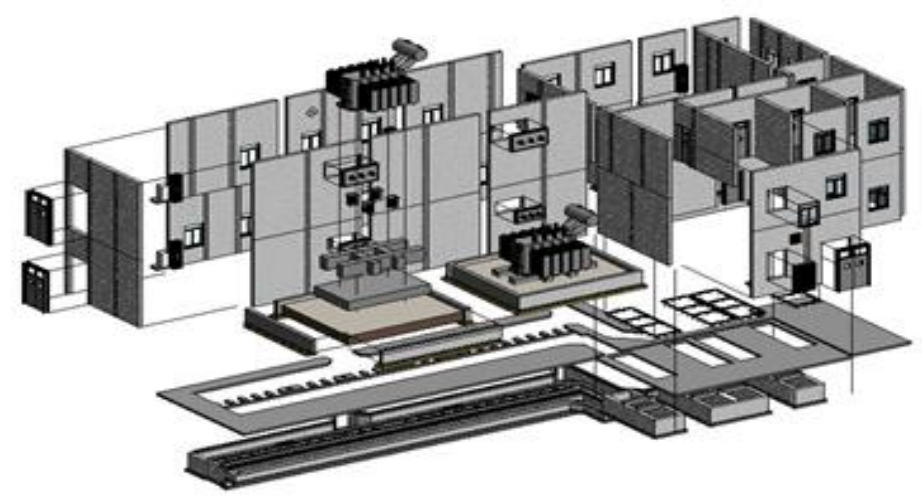

Fig. 3 Architecture exploded diagram

\section{Conclusion}

In this paper, a 35kv substation is used as the object of study and testified the feasibility of BIM technology. This research is an attempt in electric power industry, BIM technology just applied in civil construction before, but now it can be used in power construction industry, the application scope of BIM becomes wider.

BIM technology has many advantages, such as visualization design, collision detection and auto-counting quantities. Considering chinese special electric power engineering calculation rules, future research should focus on how to balance power cost management with modeling standard in order to create a model that meets rules of the 2013 edition power engineering quota; and then obtains the quantities and project price in an easier way to reduce the workload of traditional cost personnel and to enhance efficiency. 


\section{References}

[1] Hua Huang. The Whole Process of Cost Determination Method Based on BIM. Journal Science and Technology Information. Vol. 11 (2014) No. 5, p. 215-216.

[2] Hualin Shen: Substation Modeling and Quantity Statistical Based on BIM Technology (Bachelor, North China Electric Power University, Beijing, 2014). p. 1-20.

[3] Qin Guo. Analysis of Differences between Autodesk Revit and Common Architectural Design Software. Journal of Engineering Design Management. Vol. 20 (2013) No. 3, p. 14-16.

[4] Huisheng Wang: The Application Research of BIM Technology in Green Civil Building Design (Master, Beijing University of Technology, Beijing, 2014). p. 2-15.

[5] Yuemao Li, Shazhou. Shazhou 750kv Digital Substation-BIM and Digital Transfer. Construction Quality. Vol. 32 (2014) No. 1, p. 70-74.

[6] Junwei Li, Weizheng Huang, Xufeng Wang. The Study on Engineering Investigation Design Stage Based on BIM Technology. Construction Economy. Vol. 36 (2015) No. 9, p. 117-120.

[7] Yan Xu: Study on Application and Promotion of BIM Technology in Electric Power Engineering Cost (Master, North China Electric Power University, Beijing, 2015). p. 11-20. 